\title{
PORTABLE DEVICE FOR WOMEN SECURITY
}

\author{
Ashlesha Wankhede ${ }^{1}$, Ashwini Velankar ${ }^{2}$, Priyanka Shinde ${ }^{3}$ \\ ${ }^{1}$ Student, Electronics \& Tele-Communication Dept., Bharati Vidyapeeth's College of Engg., for Women, Pune, \\ Maharashtra, India \\ ${ }^{2}$ Student, Electronics \& Tele-Communication Dept., Bharati Vidyapeeth's College of Engg., for Women, Pune, \\ Maharashtra, India \\ ${ }^{3}$ Student, Electronics \& Tele-Communication Dept., Bharati Vidyapeeth's College of Engg., for Women, Pune, \\ Maharashtra, India
}

\begin{abstract}
Today's world is full of rush and most of the women work independently to support their family. They have to work till late night. For such women, safety is the most important requirement. The security issue for such women comes forward because cases of harassment and rapes on those women are increasing. Best suitable system for those women will be a portable system which the women will be able to carry will her and easy to use. Portable system will generate a shock which will make to attacking person to get back. After generation of shock the message will be sent with the help of Global System for Mobile Communication (GSM) on the particular number stored and the location of those women is traced with the help of Global Positioning System (GPS). If the message is not checked by the particular number mentioned, the system will continuously give the call until the message is checked by the particular number mentioned.
\end{abstract}

Keywords: AVR atmega328P, GSM, GPS, shock generator circuit. $* * *$

\section{INTRODUCTION}

Our life has became to fast now-a-days. To remain part of this fast life women also works a lot to survive and supports their family. They work at different places like IT firms, BPO's, call centres and so many places like it. The call centre and BPO jobs are scheduled for late night. After completion of their duty they have to go home late night so anything may happen at such timings as well as there is a chance of harassment at lonely places. For this purpose portable system is designed which can be easily carried with the women.

In this paper we described about our system. Section 2 includes the hardware used in detail. Section 3 includes the block diagram of the system. Section 4 gives the actual working of the system. Section 5 shows the conclusion and future scope and section 6 shows the references.

\section{HARDWARE USED}

System consists of

\subsection{AVR Atmega328P}

In this system we can use an ARM processor can also be chosen but we have choose AVR atmega328P due to its small size. It is an 8-bit high performance microcontroller of Atmel's Mega AVR family with low power consumption $(0.6 \mathrm{~mA} / \mathrm{MHz})$. It has flash programmable memory of $32 \mathrm{kbytes}$. Maximum operating frequency is $20 \mathrm{MHz}$ 's It has $28 \mathrm{I} / \mathrm{O}$ pins. AVR atmega328P is heart of our system.

\subsection{GPS Module}

Global Positioning System (GPS) is used here to trace the location of the woman. In this, the GPS satellites transmit signals to a GPS receiver. Here SIM28m GPS is used.SIM $28 \mathrm{~m}$ has maximum update rate of $10 \mathrm{~Hz}$. the module supports up to 66 channels.

GPS module continuously transmits serial data in the form of sentences according to NMEA standards. The latitude and the longitude values of the location are send. Table for NMEA output sentence is as shown below:-

Table 1: NMEA output sentence

\begin{tabular}{|l|l|}
\hline Option & Description \\
\hline GGA & Time, Position and fix type data \\
\hline GSA & $\begin{array}{l}\text { GPS receiver operating mode, active satellites } \\
\text { used in the position solution and DOP values }\end{array}$ \\
\hline GSV & $\begin{array}{l}\text { The number of GPS satellites in the view satellite } \\
\text { ID numbers, evevation, azimuth and SNR values. }\end{array}$ \\
\hline RMC & $\begin{array}{l}\text { Time, date, position, course and speed data. } \\
\text { Recommended minimum navigation information. }\end{array}$ \\
\hline VTG & $\begin{array}{l}\text { Course and speed information relative to the } \\
\text { ground }\end{array}$ \\
\hline
\end{tabular}

\subsection{GSM Modem}

Global System for Mobile Communication (GSM) is the modem which accepts the SIM card and it operates just like a phone. These modems are frequently used to provide mobile internet connectivity and also used for sending and receiving SMS and MMs.GSM is a modem device with a serial, USB or Bluetooth connection. 


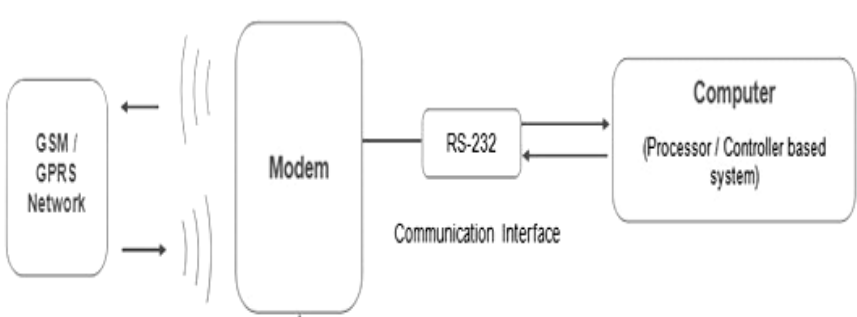

Fig -1: GSM/GPRS module

\subsection{Shock Generator Circuit}

Electric shock generator is an electronic device that produces voltage around $1200 \mathrm{mv} \&$ current of 3microamp.Electronic shock generator is fixed into the sandal. Whenever the push button is triggered the shock is generated on to the tip of the sandal. In shock generator circuit the concept of mosquito bat is used. It consists of AC to DC converter, oscillator and a net or grid.

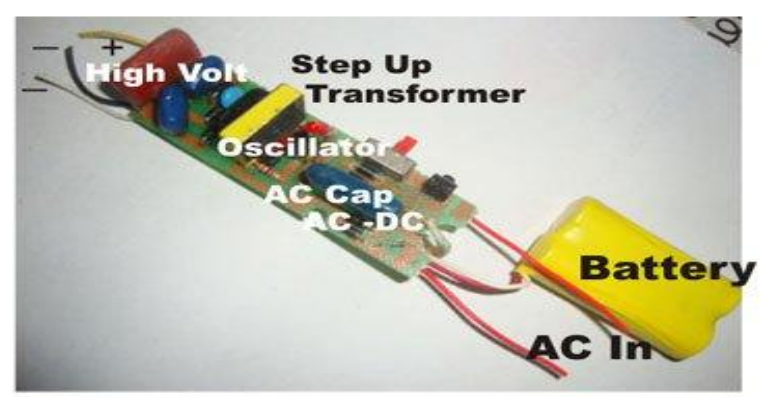

Image -1: Shock generator circuit

\subsection{RS232}

RS232 IC is used to convert TTL/CMOS logic levels to RS232 logic levels. The controller operates at TTL logic level $(0-5 \mathrm{v})$ where as the serial communication in GPS \& GSM works on RS232 standards $(-25 v$ to $+25 v)$. Thus to convert TTL logic levels to RS232 logic levels. Thus, the intermediate link is provided through RS232.

\section{BLOCK DIAGRAM OF SYSTEM}

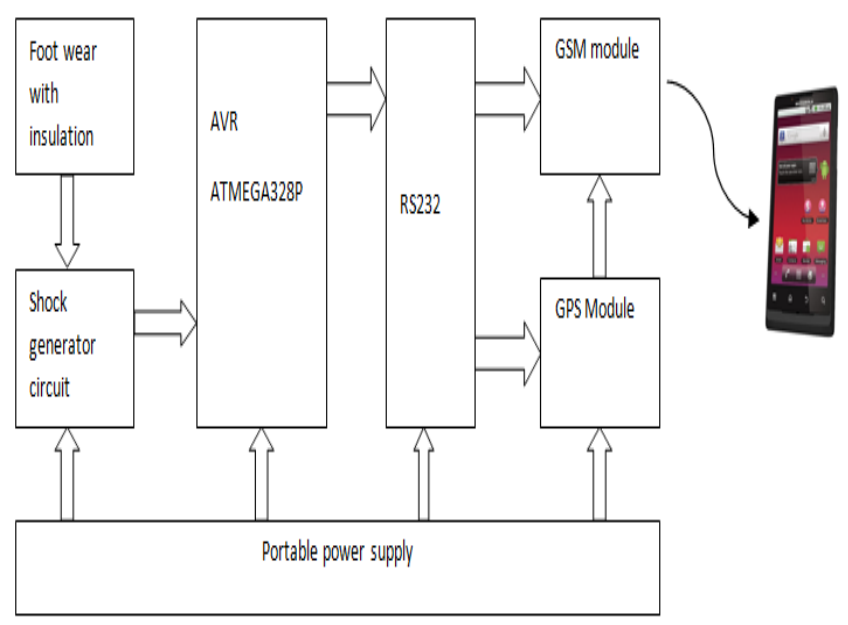

Fig-2: Block diagram of System

\section{ACTUAL WORKING OF SYSTEM}

As this is the portable system, the shock generator circuit is placed in the sandal. That is as shown in figure below

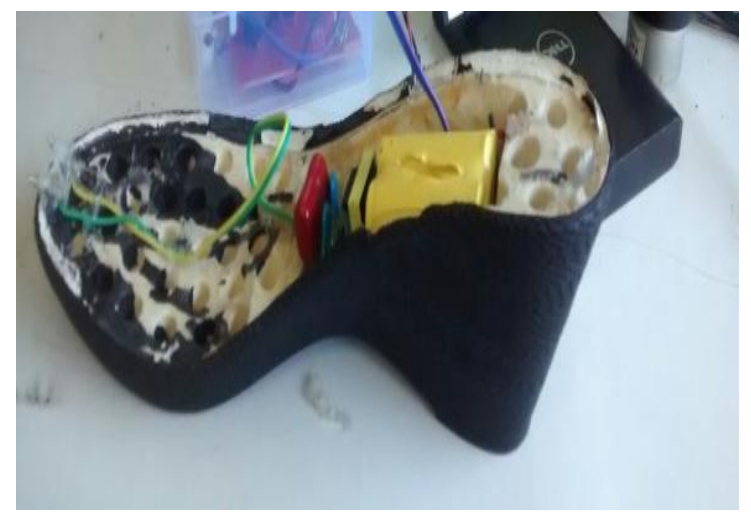

Image-2: Side view

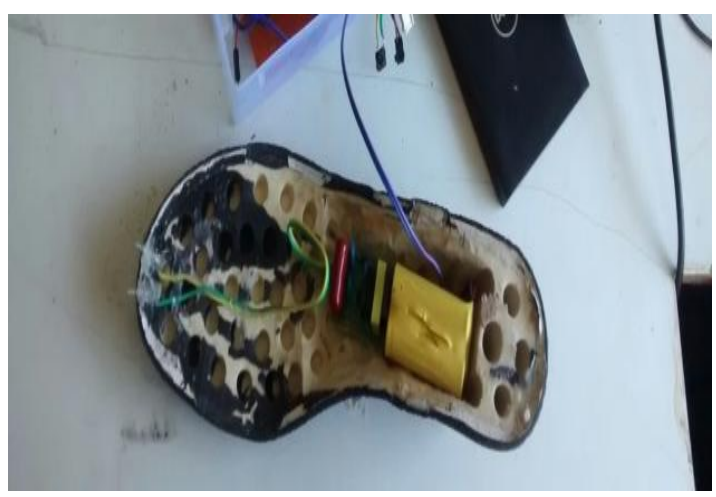

Image-3: Top view

All remaining circuit is placed in a side bag. If someone will try to harass the woman, the woman will trigger the push button switch. As soon as the button is pressed it forms a path and a shock is generated at the tip of the sandal. As the shock is generated the AVR microcontroller will send signal towards the GPS and GSM through RS232. GPS will give the location message (latitude and longitude) to the GSM and GSM will send a message that the woman needs help. It is as shown below.

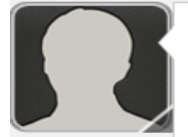

Emergency! I need help at location http://www.latlong.net/c/ ?lat $=20.753883 \&$ long $=78.61324$ Received: 11:37AM via AirTel

Image-4: Message sent on stored number

There is a facility that if the message is not checked by that particular number the system will continuously give a call on that number as long as he/she does not reject that call. This is the most important advantage of the system. And also we can add ' $n$ ' numbers while programming, if it is not checked by first number the call and message will be sent to the next and so on. So we can guarantee on women's' safety. 


\section{CONCLUSION AND FUTURE SCOPE}

Security is the most important factor for safety of women. In this paper we have discussed in details, how easily the women can be protected from harassments and rapes which are increasing day-by-day. As this system is wired system, in future it can be made wireless using Bluetooth's and also the sandal can be made waterproof.

\section{ACKNOWLEDGMENTS}

We would like to take this oppurtunity to express true sense of gratitude towards our project guide Prof. R. R. Jain for her valuable co-operation and guidance that she gave us throughout the project.We would also like to thank our head of department Prof. Dr. S. R. PATIL \& Prof. S.M.RAJBHOJ for inspiring us and providing all lab facilities and internet,which made this project very convenient.Once again,we heartly thank to all people who supported and encouraged us and without whom this project would be just like breaking the hard shell of nut.

\section{REFERENCES}

[1] Annu Kumari, Shikha Tripathi, Sandeepti Singh, "Eve Teasing Avoidance Gadget Along with Healthcare", International Journal Of Engineering Research\& Management Technology ,Electronics and Communication Engineering, SRM University NCR Campus Modinagar India, March 2014.

[2] Thouong Le-Tien, Vu Phung-The "Routing and Tracking System for Mobile Vehicals in Large Area", Fifth IEEE international Symposium On Electronic Design, Test \& Aplication Dept. Of Electrical Electronics Engg, HCM University Of Technology, Vietnam in 2010.

[3] "A Mobile Application for Women Safety", -Times of India, Dec 03-2013.

\section{BIOGRAPHIES}

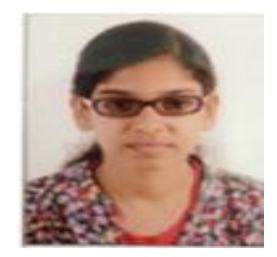

Ashlesha Wankhede, Student, Bharati Vidyapeeth's College Of Engg. For Women, Pune.

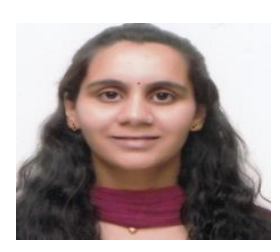

Ashwini Velankar, Student, Bharati Vidyapeeth's College Of Engg. For Women, Pune.

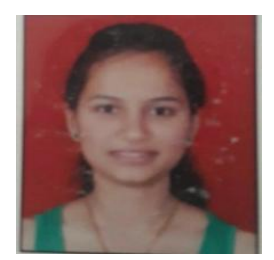

Priyanka Shinde, Student, Bharati Vidyapeeth's College Of Engg. For Women, Pune. 